\title{
Last 2 Nights
}

National Cancer Institute

\section{Source}

National Cancer Institute. Last 2 Nights. NCI Thesaurus. Code C136326.

The period of time consisting of the previous night and the night before the previous night. 